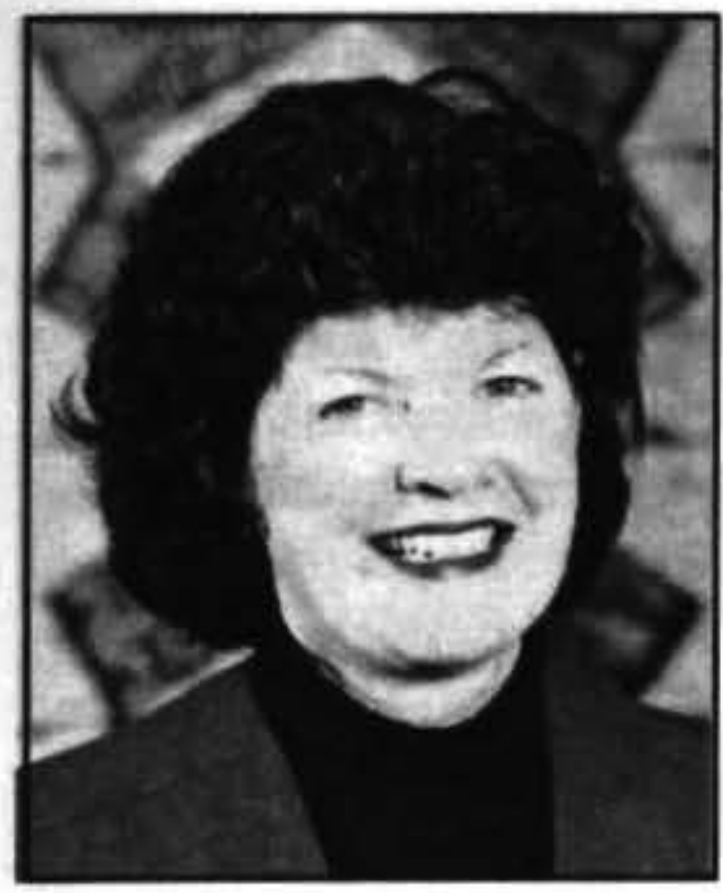

MANAGEMENT PRACTICE AND EMPLOYEE MENTAL HEALTH: AN OCCUPATIONAL SAFETY PERSPECTIVE

\author{
Cathy Robertson
}

Management Consultant

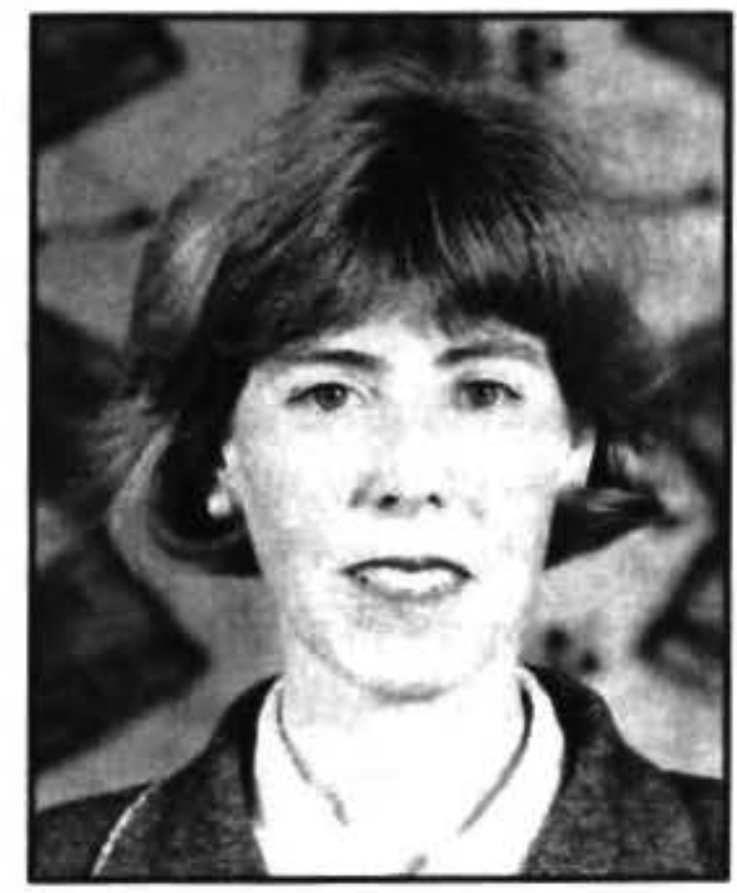

Felicity Lamm

\author{
Department of Management and Employment Relations \\ Auckland University
}

\begin{abstract}
There has hitherto been little attempt to investigate the links between management malpractice, mental health and occupational health and safety. In this paper the development of criteria for a viable methodology to assess the possibility of the existence of this link, has been developed. A semi-structured questionnaire was devised and used in a pilot study which revealed a connection between poor management techniques and mental ill-health. Some of the selected people who were invited to participate declined for fear of further intimidation. The analysis of the pilot study is discussed and the results indicate that there is a need for further, more detailed research to establish and quantify factors contributing to poor mental health in employees.
\end{abstract}

Keywords: Work Stress; Mental Health; Management Practice; Workplace Bullying; Occupational Health and Safety.

This paper reports a pilot study which endeavours to identify the types and outcomes of management malpractice with an emphasis on the health effects of employees as well as linking management malpractice with the costs to the individual employees. Currently, there is a tendency among many managers and occupational health and safety (OHS) inspectors to adopt a narrow view of what constitutes a hazard, which is one that causes acute, physical injuries (Lamm, 2000). Frequently poor management practice, such as bullying, is not regarded as a hazard but rather as a variable influencing worker productivity. Instead, there is a great deal of rhetoric about improving HR processes such as performance management (Cummings \& Worley, 1997) reward systems analysis (Wilson, 1995), worker involvement and participation (Marchington, 1995). There is little attempt to make the links between poor management practice, workplace hazards and poor productivity.

It is acknowledged that demotivational and abusive management practices place employees under excessively high levels of stress, which can lead to chronic mental ill health. However, the New Zealand OHS case law shows that the Department of Labour's enforcement emphasis is on trauma injury and not occupational mental ill health (Lamm, 2000). One reason for this is that the definition of 'hazard' under the Health and Safety in Employment $A c t, 1992$ is too vague to consider applying it to stress related ill health. Typically, employees who have been victimised at work are forced to take legal redress under New Zealand's industrial relations law, in the form of a personal grievance. There is no existing procedure through which organisations are held responsible for the mental health of their employees by enforced compliance with occupational mental health and safety standards.

\section{Mental Health Problems in New Zealand}

The extent of mental health problems and their causes within the New Zealand population is largely unknown. Nevertheless, it is interesting to note that out of a total of 33,210 in-patient days during $1996 / 1997$, of those treated for mentally related disorders, 536 were for alcohol dependence, 164 for drug dependence, 527 for nondependent drug abuse, 145 for acute stress reaction, 399 for depressive disorder and 506 for adjustment reaction. These total $6.9 \%$ of in-patient days and represent the mental disorders most likely to fall in within the types of conditions for which the respondents in this study were treated.

However, in its analysis of Mental Health Data 1994, the New Zealand Health Information Service admits that, "be- 
cause the data which is currently available represents only those patients admitted to hospital, the true prevalence of psychiatric illness in New Zealand can not be determined from the data," (New Zealand Health Information Service, 1998: 8-9). The data provided in the above statistics excludes community-based mental heath programmes and numbers of patients treated by private practitioners.

Therefore, it is argued that there is a need to establish more clearly (a) the true extent of mental illness in employees and (b) in what ways and to what extent mental illness is connected to poor management practice.

\section{Management Malpractice and Stress}

The literature acknowledges that stress threatens the mental health of employees and occurs across all levels of the workplace, in all occupations, across all ages and is a world wide problem (Bohle \& Quinlan, 2000). For example, Kawakami, (1992) shows that job unsuitability and poor human relations at the workplace are risk factors for longlasting depressive symptoms among Japanese blue-collar workers.

Further, there are a growing number of studies that show that management malpractice in the form of bullying increases the likelihood of victims experiencing stress-related illnesses such as those associated with mental health (eg Quine, 1999). Making the connection between bullying and the victim's mental health, Rees argues that:

\section{The potential for bullying in the workplace has been heightened by several managerialist values and techniques: the fundamentalist claim that 'we know best', ridiculing the past, and mechanisms of con- trol such as an intolerance of critics (1995:197-198).}

Guest, (1998) goes further by stating that stress is increased when the psychological contract between the employer and the employee is breached, namely that the employer is either no longer able to promise the traditional career and job security or they violate their promises. Robinson and Rousseau (1994) also found that violations of the psychological contract correlated with a more pronounced dissatisfaction with the organisation and a higher staff turnover. Britton's (1995) commentary of ill academic and non-academic staff clearly shows that a breach of trust by the employer has a propensity to increase stress related illnesses among employees. She states:

They [staff] love the university, and suddenly they perceive it as having betrayed them because they are now fearing for their job, or are involved in sacking other people, or are left behind with enormous workloads and no guidelines on how to manage these demands. They perceive no support or thanks for their efforts to manage these problems, so each of those groups wakes up feeling dread because they have lost control...it is like a breakdown of a marriage or, for people who leave the university, $a$ bit like death...I encourage people...to record it as a workers' compensation but they are almost always anxious about doing that in the present climate for fear they may be victimised for being stressed and for not coping (1995: 222223).

Typically remedies applied to reducing stress centred on the victim's ability to manage the situation. Bohle and Quinlan (2000) are highly critical of the narrow managerial approach which lays claim to legitimacy by using psychologists and creates a blame the victim culture. Instead, they argue that a more holistic approach which considers a wide range of factors is more useful. Moreover, there is a propensity among occupational psychologists to focus on the health aspects of the stressed individual as opposed to injuries caused by stress (Slappendel, 1995). Therefore, it is equally important to determine in what ways, and to what extent, management practice affects employee mental health, and, while not directly dealt with in this paper, to understand the extent and nature of general organisational factors in injury causation.

\section{Legal Remedies}

Although Britton encouraged her clients to seek workers' compensation, it is questionable as to whether such compensation claims would be successful in many of the Commonwealth jurisdictions, and whether legal remedies will reduce or eliminate management malpractice. Barrett (1998) notes that employees in the United Kingdom have difficulty in seeking redress for occupational stress-related illness. She questions the appropriateness of common law litigation in the United Kingdom as a means of claiming compensation for psychiatric illness as a result of negligence of another person.

In New Zealand it is unlikely that employees suffering from work-related illnesses will receive workers' compensation payments. Instead victims seeking compensation for mental ill-health as a result of management malpractice are forced to seek remedies in the Employment Court. However, the provisions under the New Zealand Health and Safety in Employment Act, 1992, have the potential to provide more protection for such individuals. The fact that workplace hazards are insufficiently defined under Act may provide an inclusive interpretation of the law, although there are few, if any examples where this has occurred.

Section 7 of the New Zealand Health and Safety in Employment Act, 1992 defines a hazard as follows:-

Where there occurs any accident or harm in respect of which an employer is required by section 25 (1) of this Act to record par- 
ticulars, the employer shall take all practicable steps to ensure that the occurrence is so investigated as to determine whether it was caused by or arose from a significant hazard.

Section 25 (1) requires "every occurrence of serious harm to an employee at work, or as a result of any hazard to which the employee was exposed while at work, in the employment of the employer, to be recorded and registered in a register."

Part one of the Act defines harm as illness, injury or both, and to harm, harmed and unharmed have corresponding meanings. The Act defines "hazard" as "an activity, arrangement circumstance, event, occurrence, phenomenon, process, situation or substance (whether arising or caused within or outside a place of work) that is an actual or potential cause or source of harm; and "hazardous" has a corresponding meaning." Although one has to question why the New Zealand OSH Service pursues very few breaches of the Act that involve ill-health, it is clear that, given the above descriptions of hazard and harm, a causal link between mental ill-health and poor management practices may be difficult to prove in a court of law.

\section{Management Practices}

In this paper, it is shown that management malpractice leading to employee mental ill health can take many forms. In New Zealand the most common are: harsh and oppressive employment contracts, breaching psychological contracts, the systematic use of fear as a motivational tool by superiors, and harassment on the basis of gender or ethnicity.

Under the Employment Contracts Act, 1991, harsh and oppressive individual employment contracts are one of its outcomes. Set within a context of high unemployment, a laissez-faire approach by government and no legal recognition of trade unions, the Employment Contracts Act, 1991 has fostered an imbalance of power in employment relationship that favours the employer (Rasmussen et al, 2000). Studies show that a "take it or leave it" style of bargaining is common, particularly among service and clothing workers (Rasmussen \& Lamm, 1999). The New Zealand Industrial Relations Services show that not only has there been a dramatic rise in the number of personal grievance cases filed in the Employment Tribunal and Court, but also the number of personal grievance cases successfully bought by employee plaintiffs has increased considerably during 1993-1998.

Deliberate breaching of the employment contract and/or the psychological contract by pressurising employees to accept contrary and detrimental contractual arrangements can also be described as management malpractice.

So too are the practices of constantly shifting the rules and goals under the guise of change management. Often, management consultants (the so-called gurus) are employed as change agents for politically motivated managerial reasons which have little to do with benefiting either the organisation or its employees. According, to Britton (1995) employee exclusion from decision making processes affecting their welfare is prevalent in poorly managed change initiatives.

Using fear as a managerial tool has been identified as a management malpractice. Some of the fear tactics used are: Threatening behavioural characteristics - "standing over" employees. The use of abusive language or issuing of harsh instructions. Making covert threats which imply that exposing bullying behaviour will result in more victimisation of the employee. Conducting threatening performance reviews as implicit disciplinary procedures. Altering performance reviews after the documents have been signed by the employee.

One of the most recognised malpractices is discrimination, for example, on the grounds of sex, age, religion, marital status. Discrimination can be perpetrated overtly, such as blocking promotion on the base of race or gender, or covertly, such as deliberately excluding an individual from group social activities or imposing heavy workloads compared to other staff members.

\section{Key Questions}

Given that there are few New Zealand empirical studies on the effects of management malpractice on employees' well-being, there still remain unanswered questions. The key questions driving this pilot research are: What are the types of management malpractice? What are the outcomes, particularly health effects, of the malpractice? What are the costs of management malpractice to the individual employees?

By undertaking an initial investigation it is hoped that the findings of this paper will provide a platform for a deeper and more extensive analysis of the mental health state of employees in New Zealand.

\section{Methodology}

This study is exploratory and the authors have adopted a qualitative approach in order to examine the feasibility of the developing a methodology by which a set of criteria can be identified linking poor mental health in employees to inappropriate management techniques (Nueman, 1994). The intention here is to use the criteria as a springboard to conduct further research across a wider section of the population and thus gain a deeper understanding of the problem.

The sample selected for this pilot study was based on a confidential client data base and was intended to cover a diverse range of people. As Tables 1 and 2 illustrate, the respondents represent different occupations, gender, ages, 
ethnicity and social background. Most importantly, they had no experience of mental illness prior to their exposure to the management malpractice. All the respondents had undergone counselling after experiencing poor mental health as a result of abusive management practices.

\section{Table 1. Biographical Profile of Respondents}

\begin{tabular}{ccc}
\hline $\begin{array}{c}\text { Age of } \\
\text { Respondent } \\
\text { at Time of } \\
\text { Interview }\end{array}$ & Gender & $\begin{array}{c}\text { Country of } \\
\text { origin } \\
\text { /ethnicity }\end{array}$ \\
\hline & Female & England \\
43 Years & Female & N.Z. Maori \\
32 Years & Female & N.Z. Pakeha \\
28 Years & Male & S. Africa \\
49 Years & Male & Asia \\
29 Years & Female & Scotland \\
52 Years & Female & N.Z. Pakeha \\
37 Years & Female & Canada \\
65 Years & & \\
\hline
\end{tabular}

Eleven respondents were invited to participate in the pilot study. Three declined for fear of being intimidated, despite being provided with a guarantee of anonymity. It should also be noted that because the smallness of the sample, 8 respondents, the findings cannot be extrapolated to the wider population but instead provide an indication of the forms and outcomes of management malpractice (Nueman, 1994).

\section{Table 2. Employment Profile of Respondents}

\begin{tabular}{cc}
\hline $\begin{array}{c}\text { Respondents by } \\
\text { Occupation }\end{array}$ & $\begin{array}{c}\text { Length of Service } \\
\text { Years }\end{array}$ \\
\hline Banker & 15 \\
Nurse & 6 \\
Laboratory Technician & 5 \\
Engineer & 5 \\
Marketing Executive & 2 \\
Customer Service Clerk & 3 \\
Retailer & 3 \\
Receptionist & 4 \\
\hline
\end{tabular}

Because of the exploratory approach adopted and the sensitive nature of the study, face-to face interviews were conducted. A semi-structured questionnaire was designed to capture information on the forms and outcomes of management malpractice. The information is essentially descriptive and charts the experiences of the respondents. The questions asked in the study can be grouped under the following headings: A description of management malpractice; a description of human resource management practices; a description of the respondent's feelings of the experience; ill-health experienced by the respondents as a result of management malpractice; injuries incurred as a result of work-related stress, the financial and personal costs to the individual; wider implications of management malpractice; summary description of management practices

\section{Management Malpractice}

The analysis of the data on management malpractice and the outcomes of management malpractice can be summarised as follows:

\section{Unwarranted Pressure Exerted by Manager}

All eight respondents had been placed under severe pressure by their managers. Seven had experienced overt bullying tactics such as being shouted at, falsely accused of fraud, being "stood over" and forced to sign documents out of fear of losing their positions.

\section{Abusive Performance Reviews}

Six respondents had experienced traumatic performance reviews resulting in feelings of fear and high anxiety. Some examples of the abusive use of the performance management procedures contained in the replies were: Being marked down for being too thorough when the job itself demanded a particularly high level of accuracy; Being stood over to sign a performance review prior to completion by a manager; Being told by a manager that it was not necessary to sign an excellent performance review and discovering later, that the areas of high performance had been erased and reconstructed as "poor" and subsequently presented to senior management in order to give an impression of poor performance by the respondent. Any attempt to question the manager is met with threatening response. Being called into an impromptu, sudden performance review in which peers and supervisors were invited to participate, during which the manager shouted and pounded the table in an incoherent rage; Being issued with a verbal warning during a performance review for being unable to rectify a situation which the manager who was conducting the review had themselves caused.

\section{Broken Psychological Contract}

The eight respondents felt that they had put much extra effort into their work and that superior achievements which they had achieved for their organisation had neither been recognised nor rewarded. For example, one respondent regularly exceeded sales targets and built the business up to a large turnover, exceeding budget by $200 \%$ within twelve months. The manager subsequently doubled the sales target and halved commission, making it impossible for the respondent to earn a "liveable" commission. This considerably reduced the respondent's salary and resulted in symptoms of anxiety and depression.

\section{I was unable to concentrate, had poor}

memory and just wanted to stay away from 
anyone and go to bed which is not my normal extrovert self. I was sure that I was about to be terminated and panicked by the prospect of no money and being unable to pay my mortgage and provide for my children.

\section{Outcomes}

\section{Effects on Health}

Seven respondents had consulted a medical practitioner and were all subsequently referred for counselling. Typical symptoms were; heart palpitations; sudden onset of high blood pressure; development of alcohol and drug dependency; loss of appetite; loss of sleep; severe allergic reactions; development of sporadic short term memory loss; stomach cramps; depression; anxiety; lack of self esteem; and fear.

\section{Accidents}

Two respondents were involved in a near miss and potentially fatal motorcar accidents as a result of inattention through work-related anxiety. None had any near miss work based accidents although it is possible that the sample of respondents is biased, as they were all employed in relatively physically safe occupations. Nevertheless, this result supports criticisms made by Bohle and Quinlan (2000) of the undue emphasis placed on individual employee causation of ill-health and injuries despite the evidence to support a wider consideration of organisational factors when looking at causes of work-related ill-health and injury.

\section{Costs to Individuals and to the Companies}

All of the respondents felt that not only had their performance at work been adversely affected but they had incurred both personal and monetary costs. Six of the respondents consulted with counsellors, stress management consultants and medical practitioners at a total cost exceeding NZ\$10,000. One respondent took six months to regain confidence through retraining and being coached by a career consultant at a total cost including lost salary, of approximately NZ $\$ 36,000$.

Seven of the eight respondents resigned or are actively seeking employment. There is no data available from which the cost of re-recruitment to the relevant companies can be assessed.

Two respondents were offered counselling by in-house industrial psychologists but turned this down for fear of being blamed for the problem and further victimisation. West and Reynolds (1995) note that industrial, organisational and clinical psychologists have largely failed to address the issue of the acceptability of different approaches to stress management to those for whom such services are provided.

One respondent approached their professional association for advice but due to ignorance and lack of support for the problem, opted for private treatment. All six respondents who had taken sick leave had named influenza to their companies, as the reason.

\section{Legal Action taken by Respondents}

One respondent took legal action under the Employment Contracts Act, 1991 and the case was heard in the Employment Tribunal. The remaining seven refrained from doing so for fear of losing their positions or being subject to victimisation.

\section{Effect on Other Staff Members}

Two of the eight respondents were subsequently excluded from staff events or victimised and undermined, leading to further feelings of isolation.

Three respondents reported particularly high staff turnovers and time taken for sick leave within their organisations. For example: Nine resignations out of fifteen support staff in six weeks; Ten out of twenty five peers taking sick leave within two months for stress related sickness; Six resignations out of fifteen highly qualified professional staff in one year.

One respondent, a supervisor, felt guilty and anxious over the way a particular member of staff was being treated. Although the staff member had performed exceptionally well in terms of generating new business, the newly appointed departmental manager threatened the staff member with physical violence if sales did not improve. As a result the staff member resigned. The respondent felt responsible for the supposed "non performance", the manager's threatening behaviour, the staff member's resignation and worried about the welfare of the staff member's family.

\section{Summary of Management Practices}

The respondents were clear about what constitutes good management skills. These were: supportive; honest; downto-earth; providing clear objectives and instructions; decisive; firm but fair performance expectations; consultative approach; appreciative of extra effort; creating an atmosphere of trust; willing to listen; encouraging.

They were equally vocal about poor management traits and listed them as: unsupportive; dishonest; arrogant; degrading; fear creation and bullying tactics; inflexible; autocratic; unattainable and distant; uncommunicative; unwilling to listen to ideas; constantly changing rules and goals.

The above results show that respondents had reasonable expectations of what constitutes good management and fair perceptions of the nature of poor management skills and characteristics. 


\section{Discussion}

From the analysis of the data it is clear that all the respondents who participated in the exercise suffered some degree of mental ill health as a result of poor management practices. The data also reveal that management malpractice in the form of unchecked bullying, insufficient victim support and lack of health and safety systems creates a dysfunctional organisation as well as incurring costs for both the individual and the company.

Thus, in order to avoid these problems it was clear from the interviewee data that employers need to develop and implement procedural tools as a way of improving management practices that in turn will reduce the mental stress of employees. Such tools should also be an essential part of an employer's organisational strategy that will enhance employee performance.

For New Zealand companies, having an OHS policy and system is a legal requirement. However, typically the emphasis has been on safety with little or no consideration for mental health, leaving the company vulnerable to litigation by either the OSH Service or by employees. Therefore, there is a need to create a new OHS model that incorporates the notion of mental health and safety. Such a model should also include a high degree of employee participation (not directly required under the Health and Safety in Employment Act, 1992). Studies by Weil (1991) and Pil and MacDuffie (1996) have shown that there are strong empirical links between high-involvement work practices, lower injury and illness rates and improved economic performance. Furthermore, Pil and MacDuffie (1996) state that such practices are most effective as part of a larger bundle or system that includes complementary human resource practices.

A large New Zealand retail company is a good example of how the combination of both good management practices and human resource management can be used to gain a significant share of the New Zealand market. The owner maintains that by combining strategic planning, marketing strategies with the function of human resource selection, development, training and participative initiatives and health and safety measures, his company has achieved a billion dollar annual turnover (Listener, July, 2000:18). Of particular relevance to the findings of this paper was the introduction of strategies to ensure a management motivational style that fostered good will and enrichment. By combining these functions, the company acknowledges the need to promote mental health in its employees through its development of a strong sense of company cultural values and the commitment of its managers to communicating well with their staff and listening to their needs. At the same time it sets clear performance goals and provides the support, which assists employees in achieving those goals.

It is necessary for companies not only to implement longterm solutions to counter management malpractice and employee ill-health, but also to adopt strategies that will ensure the retention of organisational core competency through its skilled, qualified staff. One of our case studies is a good illustration of poor management practices that lead to high staff turnover. This professional firm lost 35\% of its skilled, professionally qualified specialist staff in a twelve month period.

It is also argued that that the emphasis on the victim and the resultant victim blaming explanations are not useful in reducing the level of ill-health and loss of staff. Thus, question is, "How productive are those disciplines such as psychology, which have a tendency to apply an intellectual framework that concentrates solely on the individual behaviour of the victim?"

In summary, New Zealand companies need to first accept the principle of creating a mentally healthy workplace based on employee participation. This may be more difficult in New Zealand than in other Australian states as employee participation in workplace health and safety is not fostered in either the Health and Safety in Employment Act or the Employment Contract Act. Next, there is a need to implement holistic, participative strategies that will not only result in a reduction in the stress among employees but will also reduce the polarisation between management and employees on workplace health and safety issues, and improve labour commitment and productivity.

\section{Future Research}

The purpose of this paper is to explore the links between management malpractice and occupational health and safety. It is also intended to provide a criteria of management malpractice and its outcomes as a way of demonstrating the health, safety and monetary costs to the individual and to the company.

However, this pilot study raises more questions than it answers and the issues raised here require further analysis of the causes and the effects on safety of poor mental health in employees. In addition, there are problems with the research design that need to be taken into consideration. First, the small sample of respondents were restricted to those employed in the service and specialist professional fields. Secondly, statistical data from the New Zealand Health Information Service by its own admission does not, in present format, reflect the true prevalence of psychiatric illness in New Zealand. Thirdly, no statistical analysis exists which relates mental illness to work-related stresses. Finally, there are no existing criteria through which a set of procedures can be developed and by which employers can be held accountable for employee mental safety within Health and Safety in Employment legislation.

Therefore, in order to assess the deeper and broader extent of the problem, an in-depth analysis of mental health in the context of management practice will be required 
which includes employees from all sectors within the labour market.

\section{References}

Barrett, B. (1998) When Should there be Liability for Negligently Causing Psychiatric Illness? Work and Stress, 2, 101-111.

Bohle, P. and Quinlan, M. (eds) (2000) Managing Occupational Health and Safety in Australia: A Multidisciplinary Approach. Melbourne: Macmillan.

Britton, S. (1995) Some Health Costs of Managerialism. Rees, S. and Rodley, G. (eds) The Human Costs of Managerialism. Sydney: Pluto Press.

Cummings, T. and Worley, C (1997) Performance Management. Organization Development and Change. Ohio: South-Western College Publishing. Chapter 13.

Guest, D.E. (1998) Is the Psychological Contract Worth Taking Seriously? Journal of Organisational Behaviour. Special Issue, 1998.

Kawakami, H. (1992) Effects of Perceived Job Stress on Depressive Symptoms in Blue-collar Workers of an Electrical Factory in Japan, Scandinavian Journal of Work, Environment Health, 18: 195200.

Industrial Relations Service (1999) Contract: The report on current industrial relations in New Zealand, Department of Labour, Wellington.

Lamm, F. (2000) Occupational Health and Safety Regulation: A New Zealand Perspective. Bohle, P. and Quinlan, M. (eds) Managing Occupational Health and Safety in Australia: A Multidisciplinary Appróach, Melbourn: Macmillan.

Listener, (2000) Everyone Get a Bargain: Inside the Warehouse Empire of Stephen Tindall, July 22-28.

Marchington, M. (1995) in Storey, J. (ed) Human Resource Management: A critical Text. USA, Canada: Routledge.

Neuman, W. L. (1994) Social Research Methods: Qualitative and Quantitative Approaches, Massachusetts, Allyn and Bacon.
Mental Health Data 1994, 8-9.

Pil, F. and MacDuffie, J. P. (1996) The Adoption of HighInvolvement Work Practices, Industrial Relations, Vol. 35, No. 3, pp 423-455.

Quine, L. (1999) Workplace Bullying in the NHS Community Trust: Staff Questionnaire Survey. British Medical Journal Vol. 318, No. 7178, pp228-256.

Rasmussen, E. and Lamm F. (1999) An Introduction to New Zealand Employment Relations. Auckland: Longman and Paul.

Rasmussen, E. Lamm, F. and Snelders, B. (2000) New Zealand: Deregulation of Employment Relations, Occupational Health and Safety and Social Welfare in the Post-1984 period. Van Waarden, F. and Simonis, J. (eds) Deregulating Imperfect Markets. Amsterdam: Netherlands School for Social and Economic Policy Research.

Rees, S. (1995) Greed and Bullying. Rees, S. and Rodley, G. (eds) The Human Costs of Managerialism, Sydney: Pluto Press.

Robinson, S. L. and Rousseau, D. M. (1994) Violating the Psychological Contract: Not the Exception but the Norm. Journal of Organisational Behaviour, $15,245-259$.

Slappendel, C. (1995) Health and Safety in New Zealand Workplaces, Palmerston North:

The Dunmore Press.

Weil, D. (1991) Enforcing OSHA: The Role of Labor Unions, Journal of Economy and Society, Winter 30 (1) 20-36.

West, A. M. and Reynolds, S. (1995) Employee Attitudes to Work-based Counselling Services, Work and Stress, 9 (1) 1-44.

Wilson, M. (1997) Reward Systems. Boxall, P. (ed) The Challenge of Human Resource Management. Auckland: Longman Paul.

New Zealand Health Information Service, (1998) 


\section{Authors}

\section{Cathy Robertson}

Management Consultant

P.O. Box 8437

Symonds St

Auckland

cathy.robertson@xtra.co.nz

\section{Felicity Lamm}

Senior Lecturer

Department of Mangement and Employment Relations

The University of Auckland

Private Bag 92006

Auckland

f.lamm@auckland.au.nz 